\title{
Article \\ Scoring Osteoarthritis Reliably in Large Joints and the Spine Using Whole-Body CT: OsteoArthritis Computed Tomography-Score (OACT-Score)
}

\author{
Willem Paul Gielis ${ }^{1,2, *} \mathbb{C}$, Harrie Weinans ${ }^{1}$, Frank J. Nap ${ }^{3}$, Frank W. Roemer ${ }^{4,5}$ and Wouter Foppen ${ }^{2} \mathbb{C}$ \\ 1 Department of Orthopaedics, University Medical Center Utrecht, Utrecht University, \\ 3584 CX Utrecht, The Netherlands; h.h.weinans@umcutrecht.nl \\ 2 Department of Radiology, University Medical Center Utrecht, Utrecht University, \\ 3584 CX Utrecht, The Netherlands; W.Foppen@umcutrecht.nl \\ 3 Department of Radiology, Central Military Hospital (CMH) Utrecht, 3584 CX Utrecht, The Netherlands; \\ F.J.Nap-3@umcutrecht.nl \\ 4 Department of Radiology, Friedrich-Alexander University Erlangen-Nürnberg \& Universitätsklinikum \\ Erlangen, 91054 Erlangen, Germany; Frank.Roemer@uk-erlangen.de \\ 5 Department of Radiology, Boston University School of Medicine, Boston, MA 02118, USA \\ * Correspondence: w.p.gielis@umcutrecht.nl; Tel.: +31-88-755-9025
}

check for updates

Citation: Gielis, W.P.; Weinans, H.; Nap, F.J.; Roemer, F.W.; Foppen, W. Scoring Osteoarthritis Reliably in Large Joints and the Spine Using Whole-Body CT: OsteoArthritis Computed Tomography-Score (OACT-Score). J. Pers. Med. 2021, 11, 5. https://dx. doi.org/10.3390/jpm11010005

Received: 26 October 2020

Accepted: 18 December 2020

Published: 22 December 2020

Publisher's Note: MDPI stays neutral with regard to jurisdictional claims in published maps and institutional affiliations.

Copyright: () 2020 by the authors. Licensee MDPI, Basel, Switzerland. This article is an open access article distributed under the terms and conditions of the Creative Commons Attribution (CC BY) license (https: / / creativecommons.org/ licenses/by/4.0/).

\begin{abstract}
A standardized method to assess structural osteoarthritis (OA) burden thorough the body lacks from literature. Such a method can be valuable in developing personalized treatments for OA. We developed a reliable scoring system to evaluate OA in large joints and the spine-the OsteoArthritis Computed Tomography (OACT) score, using a convenience sample of 197 whole-body low-dose non-contrast CTs. An atlas, containing example images as reference points for training and scoring, are presented. Each joint was graded between $0-3$. The total OA burden was calculated by summing scores of individual joints. Intra- and inter-observer reliability was tested 25 randomly selected scans ( $N=600$ joints). Intra-observer reliability and inter-observer reliability between three observers was assessed using intraclass correlation coefficient (ICC) and square-weighted kappa statistics. The square-weighted kappa for intra-observer reliability for OACT-score at joint-level ranged from 0.79 to 0.95 ; the ICC for the total OA grade was 0.97 (95\%-CI, 0.94 to 0.99 ). Squareweighted kappa for interobserver reliability ranged from 0.48 to 0.95 ; the ICC for the total OA grade was 0.95 (95\%-CI, 0.90 to 0.98$)$. The OACT score, a new reproducible CT-based grading system reflecting $\mathrm{OA}$ burden in large joints and the spine, has a satisfactory reproducibility. The atlas can be used for research purposes, training, educational purposes and systemic grading of OA on CT-scans.
\end{abstract}

Keywords: computed tomography; image analysis; osteoarthritis; reliability

\section{Introduction}

Osteoarthritis (OA) is a leading cause of disability worldwide, with the estimated socioeconomic burden being $1 \%-2.5 \%$ of the gross national product in Western countries [1]. Until now, the search for a disease modifying drug for OA has failed. A key factor for this failure is the use of a one-size-fits-all principle in the development and testing of potential treatments. End-stage osteoarthritis is a fairly uniform disease, but etiological pathways in early disease vary strongly. There is a desire to group OA patients into phenotypes, with the ultimate aim of finding the right treatment for the right patient [2]. The APPROACH study aims to describe these different phenotypes for knee OA and validate models to predict disease progression within these phenotypes [3]. This allows for more patient specific treatments and more efficient clinical trials. The APPROACH study includes knee specific parameters, including patient reported outcome measures (e.g., knee specific questionnaires), physical examination (e.g., knee range of motion), and imaging features (e.g., knee MRI). Additionally, more generic parameters are measured, such as general 
quality of life, physical performance (e.g., $40 \mathrm{~m}$ fast paced walk test) and biochemical marker levels in serum and urine. OA is often a polyarticular disease and the relationship between the latter parameters and knee OA will be heavily influenced by the overall OA burden in the body. However, there is no efficient and standardized method to assess this burden $[4,5]$.

Radiography is widely used for visualizing and grading structural OA. However, it has limited sensitivity for detecting structural damage because of its projectile nature; repeatability is an also issue as positioning errors are common (e.g., wide variations in joint space measurements due to inconsistent flexion of the knee) [6]. Magnetic resonance imaging (MRI) is excellent for visualizing the different tissues within a joint, but it is expensive and time consuming; for example, to obtain good-quality MRI images of multiple joints, the patient would need to lie still for hours. However, CT has several advantages. It uses ionizing radiation to produce a three-dimensional (3D) tomographic images, without the projection limitations of radiography, and is known for its excellent visualization of bone. Advances, such as iterative reconstruction have substantially reduced exposure to ionizing radiation and scanning time $[7,8]$. Low-dose CT scans provide valuable information on the bony aspects of the joints, with a relatively high signal-to-noise ratio. Whole-body Low-dose CT (WBLDCT) scans, with a scan time of less than one minute and an effective radiation dose $<3 \mathrm{mSv}$ for a $70 \mathrm{~kg}$ adult male, are increasingly used for evaluation various conditions.

In this study, we aim to develop and describe a WBLDCT-based scoring system to quantify OA burden throughout the body. We believe that the score-the OsteoArthritis Computed Tomography (OACT) score-will be especially useful for research towards personalized OA treatments. We assess the inter- and intra-reader agreement of the new score and present an atlas, with extensive image examples, that can be used for training and educational purposes, for uniform grading of OA on CT-scans.

\section{Materials and Methods}

\subsection{Study Sample and Image Acquisition}

The scoring system was developed using a convenience sample of 197 WBLDCTs acquired for diagnosis or for attenuation correction in PET/CTs in the UMC Utrecht, Utrecht, The Netherlands, between June 2011 and November 2015; the scanning was performed as part of workup for suspected cancer and vascular or infectious disease. Scans were acquired in the supine position without any contrast enhancement, with $64 \times 0.625-\mathrm{mm}$ collimation, $120 \mathrm{kV}$, and dose modulation with a reference of $40 \mathrm{mAs}$; the estimated effective dose was $<3.0 \mathrm{mSv}$ for a $70-\mathrm{kg}$ adult male. Reconstructions in the axial plane were made with 1-mm slices and $0.7-\mathrm{mm}$ increments. Joints with metallic implants were excluded. This study was approved by the local institutional review board (protocol number 15/446-C), with waiver of the need for informed consent.

\subsection{Image Assessment}

The Picture Archiving and Communication System (PACS IDS7 19.3.12; SECTRA) was used to produce multiplanar view reconstructions. Using the 197 scans we created a feasible and reproducible system for grading the severity of $\mathrm{OA}$ in each of the major joints. Then, a reference atlas was composed that could be used to teach new readers the scoring definitions. Finally, we tested intra- and inter-observer reproducibility on a subset of 25 randomly selected scans (which included a total of 600 joints).

We aimed to grade all large synovial diarthrodial joints, intervertebral discs (IVD), and facet joints. The elbow was frequently positioned outside the field of view and was therefore excluded. Degenerative disc disease (DDD) of the IVD differs from OA, as IVDs are fibrocartilaginous and not synovial joints. However, the biochemical and radiological features of DDD closely resemble those of OA [4]. Many previous OA studies have assessed the lumbar spine but, as other researchers have suggested, DDD in the cervical and thoracic spine also needs to be considered $[9,10]$. We first performed a thorough literature search to 
locate CT-based scoring systems for OA of different joints. If no viable CT-based scoring system was found, we modified the standard radiography-based scores for use on CT images. If no viable scoring system was available for a joint, we developed a new system using the classic radiographic OA characteristics (joint space narrowing, osteophytosis, sclerosis, and subchondral cysts). Each joint was graded on a scale of 0 to 3 ; thus, four grades were possible. The goal was to develop a scoring system that could be used to score all joints in a single patient within $15 \mathrm{~min}$. The process of development of the scoring system for each joint is described below. The scoring of each joint was discussed in multiple sessions between a group consisting of a MD researcher with 5 years of experiences in medical imaging of OA (WPG), a radiologist in training with a subspecialization in musculoskeletal radiology (WF), and a fellowship-trained musculoskeletal radiologist with 6 years of experience (FJN) and an associate professor, section chief of Musculo-Skeletal Research and attending Radiologist with extensive experience in developing radiologic scores (FWR) The supplementary atlas (Supplementary Materials), which contains extensive examples, can be used for training and also serves as a reference for scoring. Figure 1 presents an overview of the tibiofemoral joint, and Figure 2 shows different grades of tibiofemoral OA.

\subsubsection{Upper Extremity}

Acromioclavicular Joint

Our literature search located a single grading system for acromioclavicular joint degeneration [11]. Using 108 cadaveric joints, Stenlund et al. created a radiographic score that demonstrated satisfactory correlation with macroscopic morphological grade. However, this system was not tested for reproducibility. We used the radiographic characteristics identified by Sterlund et al. to create four grades (Table 1).

\section{Glenohumeral Joint}

We did not find a validated CT-based grading system for glenohumeral OA. Therefore, we based our score on the widely used and reliable system proposed by Samilson and Prieto that scores OA according to the size of inferior humeral osteophytes on radiographs (Table 1) $[12,13]$. As CT images offer 3D visualization of the joint, we considered osteophytes everywhere in the glenohumeral joint, i.e., inferior, anterior, and posterior humeral and glenoidal.

\subsubsection{Spine}

Degenerative Disc Disease

The system proposed by Lane et al. for grading degenerative disease of the thoracic and lumbar spine is convenient and reliable [14,15]. We modified it for use on CT images of the cervical, thoracic, and lumbar spine (Table 1). In addition to sclerosis, we considered endplate irregularity, which can be evaluated on $\mathrm{CT}$, as a sign of disease involvement of cartilaginous and bony endplates. Extensive grading 21 spinal levels would be too time consuming, thus, a concise screening of the spine is performed to identify the two most affected levels within the cervical, thoracic, and lumbar regions. For these levels the extensive grading is performed. If these scores are low, this means that degenerative changes in the whole spinal region and therefore we expect limited impact on on systemic biomarker levels and quality of life measurements. 


\section{Tibiofemoral joint (Knee)}

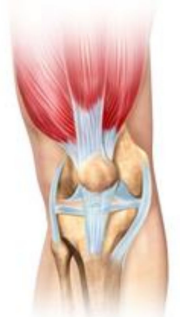

Rotate the MPR so that the sagittal plain runs trough the middle of the patella and the coronal plain is parallel to the posterior aspect of the condyles

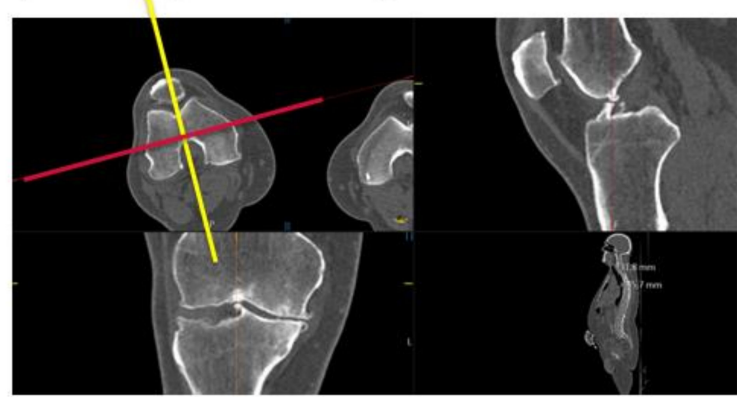

\begin{tabular}{|c|l|}
\hline $\begin{array}{c}\text { Predominant } \\
\text { view }\end{array}$ & Tibiofemoral joint (Knee) \\
\hline Settings & $\begin{array}{l}\text { Coronal, axial and sagittal } \\
\text { Oblique if needed }\end{array}$ \\
\hline Sections & $\begin{array}{l}\text { Multiplanar view, minimal slice thickness, } \\
\text { bone window }\end{array}$ \\
\hline Grading & $\begin{array}{l}\text { Left and Right } \\
\text { Joint Space Narrowing (JSN) }\end{array}$ \\
\hline & $\begin{array}{l}\text { Osteophytes (OST) } \\
\text { Cysts (CYST) }\end{array}$ \\
\hline ISN & Definition \\
\hline 0 & No joint space narrowing \\
\hline 1 & Possiblejoint space narrowing \\
\hline 2 & Definite joint space narrowing \\
\hline 3 & Obliterated joint space \\
\hline OST & Definition \\
\hline 0 & No osteophyte \\
\hline 1 & Possible / small osteophyte \\
\hline 2 & Moderate osteophyte ( 5 mm) \\
\hline 3 & Large osteophyte (>5 mm) \\
\hline CYST & Definition \\
\hline 0 & No subchondral cyst \\
\hline 1 & Presence of subchondral cyst \\
\hline
\end{tabular}

Illustration from Gettylmage

Figure 1. An example from the atlas showing the overview for scoring tibiofemoral osteoarthritis.

\section{Tibiofemoral examples per grade}

Grade 0
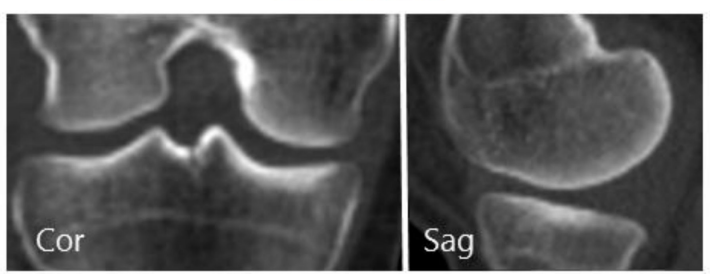

Grade 2
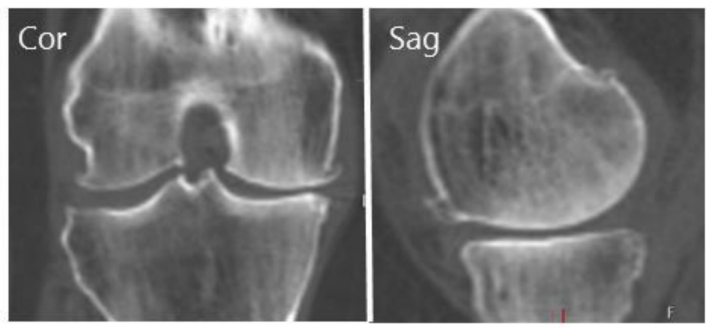

Grade 1

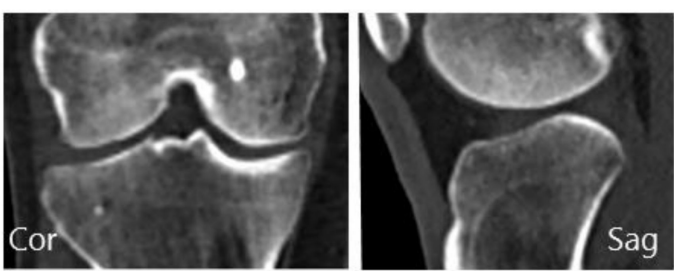

Grade 3

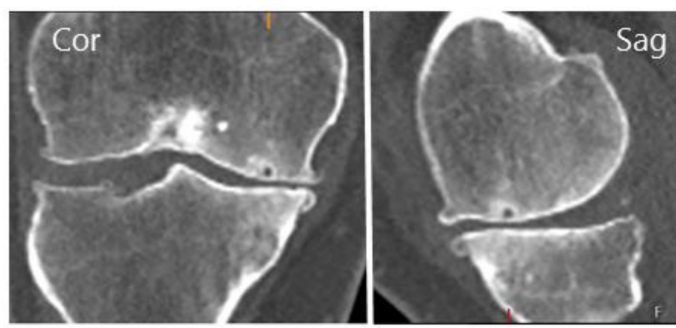

Figure 2. Example images from the atlas showing different grades of tibiofemoral osteoarthritis. 
Table 1. Definition of OACT scores for individual joints.

\begin{tabular}{|c|c|}
\hline \multicolumn{2}{|c|}{ Acromioclavicular joint } \\
\hline 0 & No osteophytes or joint space narrowing (JSN) \\
\hline 1 & Lipping and/or possible JSN \\
\hline 2 & Definite osteophytes and/or JSN \\
\hline 3 & $\begin{array}{l}\text { Definite osteophytes and/or JSN and sclerosis and/or cysts and/or bony } \\
\text { deformities }\end{array}$ \\
\hline \multicolumn{2}{|r|}{ Glenohumeral joint } \\
\hline 0 & No osteophytes or definite JSN \\
\hline 1 & Osteophyte measured less than $3 \mathrm{~mm}$ \\
\hline 2 & Osteophyte measured between 3 and $7 \mathrm{~mm}$, slight joint irregularity \\
\hline 3 & Osteophyte measured more than $7 \mathrm{~mm}$, definite JSN and/or irregularity. \\
\hline \multicolumn{2}{|c|}{ Degenerative disc disease } \\
\hline 0 & $\begin{array}{l}\text { Score } 0-2 \text { (Based on disc space narrowing, osteophytes, end plate regularity and } \\
\text { sclerosis) }\end{array}$ \\
\hline 1 & Score 3-5 \\
\hline 2 & Score 6-8 \\
\hline 3 & Score $9-10$ \\
\hline \multicolumn{2}{|c|}{ Facet joint } \\
\hline 0 & Normal facet joint space width (JSW) (2-4 mm) \\
\hline 1 & $\begin{array}{l}\text { Narrowing of facet JSW }(<2 \mathrm{~mm}) \text { and small osteophytes and/or mild } \\
\text { hypertrophy of the articular process }\end{array}$ \\
\hline 2 & $\begin{array}{l}\text { Narrowing of facet JSW }(<2 \mathrm{~mm}) \text { and moderate osteophytes and/or moderate } \\
\text { hypertrophy of the articular process and/or mild subarticulare bone erosions }\end{array}$ \\
\hline 3 & $\begin{array}{l}\text { Narrowing of facet JSW }(<2 \mathrm{~mm}) \text { and large osteophytes and/or severe } \\
\text { hypertrophy of the articular process and/or severe subarticulare bone erosions } \\
\text { and/or subchondral cysts }\end{array}$ \\
\hline \multicolumn{2}{|c|}{ Hip joint } \\
\hline 0 & Score $0-1$ (Based on joint space narrowing, osteophytes, and cysts) \\
\hline 1 & Score $2-3$ \\
\hline 2 & Score $4-5$ \\
\hline 3 & Score 6-7 \\
\hline \multicolumn{2}{|c|}{ Tibiofemoral joint } \\
\hline 0 & Score $0-1$ (Based on joint space narrowing, osteophytes, and cysts) \\
\hline 1 & Score $2-3$ \\
\hline 2 & Score $4-5$ \\
\hline 3 & Score 6-7 \\
\hline \multicolumn{2}{|c|}{ Patellofemoral joint } \\
\hline 0 & No osteophytes, joint space narrowing (JSN)/sclerosis \\
\hline 1 & Small osteophyte/lipping and mild JSN, but no defined sclerosis \\
\hline 2 & Moderate osteophytes, moderate JSN and possible sclerosis \\
\hline 3 & Large osteophytes, (near) boney contact and defined sclerosis \\
\hline \multicolumn{2}{|r|}{ Ankle joint } \\
\hline 0 & No clinical evidence of OA; joint space integrity fully intact \\
\hline 1 & Mild; osteophyte formation/lipping, possible joint space narrowing \\
\hline 2 & $\begin{array}{l}\text { Moderate; joint space narrowing evident, obvious osteophyte formation and } \\
\text { some sclerosis/cystic changes }\end{array}$ \\
\hline 3 & $\begin{array}{l}\text { Severe; near absence of joint space, severe osteophyte/cyst formation, deformity } \\
\text { of bone }\end{array}$ \\
\hline
\end{tabular}

All subscores are presented in the atlas. 


\section{Facet Joint OA}

We incorporated the grading system created by Weishaupt et al. for the lumbar facet joint OA (an adaption of the original scoring system proposed by Pathria et al.) in our score, extending its application to the cervical and thoracic spine also $[16,17]$.

We recommend the sagittal view for an easier, faster and more reproducible evaluation. Only the two most affected levels within each region are extensively graded (Table 1).

\subsubsection{Lower Extremity}

Hip

Turmezei et al. published a CT grading system for hip OA [18]. This system is highly detailed and time-consuming. In our experience, it takes about 5-10 min for an experienced reader to score 2 hips. The learning curve was long for new readers. We did not find any other grading systems for hip OA on CT and modified the score of Turmezei et al. it to obtain a more straightforward four-grade score based on their principles (Table 1).

Knee-Tibiofemoral

We found no validated CT-based grading system for knee OA. A combination of characteristics of radiographic OA as described by Kellgren and Lawrence and, more recently, by Altman et al. (joint space narrowing, osteophytosis, and subchondral cysts) was used to create the four-grade score (Table 1) [19,20].

\section{Knee-Patellofemoral}

Scoring of patellofemoral joint OA was based on the grades described by Jones et al. [21]. $\mathrm{CT}$ is acquired with extended knees, causing the patella to be located proximal to the femoral notch; in this position, it is difficult to accurately measure joint space narrowing. Therefore, we opted for a combined score that considered osteophytosis, sclerosis, and diminishment of the joint space (Table 1).

Ankle

The CT scoring system and atlas as published by Cohen et al. was used for grading ankle OA (Table 1) [22].

\subsubsection{Total OA Grade}

To test the eliability of a total score for OA in the large joints and the spine, a total OA score was calculated by summing the scores of the individual joints. Therefore, with each joint scored on a scale of $0-3$, the total score could range from 0 to 72 . (Table 1 ).

\subsection{Testing Reproducibility}

To test intra-observer reproducibility, a medical doctor and researcher with 4 years of experience (WPG) scored the same subset of 25 randomly selected WBLDCTs twice, with an interval of at least 1 week in between. To test inter-observer reproducibility, a radiologist in training, with a subspecialization in musculoskeletal radiology (WF) and a fellowshiptrained musculoskeletal radiologist with 6 years of experience (FJN), scored the same random sample of 25 scans independently. The atlas was used as reference for the grading system. In accordance with the Guidelines for Reporting Reliability and Agreement Studies, reliability was tested using Cohen's kappa for binominal grade, squared weighted kappa for ordinal grade, and two-way intraclass correlation coefficient (ICC) for consistency for the total OA score $[23,24]$. Kappa values were interpreted according to Landis and Koch: i.e., $0-0.20$ slight agreement; $0.21-0.40$ fair agreement; $0.41-0.60$ moderate agreement; $0.61-0.80$ substantial agreement; $0.81-1$ almost perfect agreement [25]. Agreement was tested using absolute agreement percentages for binominal and ordinal grades and BlandAltman and Jones plots for continuous values [26,27]. All analyses were carried out in $\mathrm{R}$ version 3.4.4 (https:/ / cran.r-project.org/) using the irr package, version 0.84. 


\section{Results}

The 197 scans used for the development of the atlas were acquired from a sample comprising $43 \%$ males $(85 / 197)$. The mean age (SD) of the patients was $54( \pm 15)$ years. Indications for scanning included vasculitis $(n=106)$, suspected infection $(n=57)$, and suspected malignancy $(n=34)$. The 25 scans included in the reliability analyses were from a patient subset that comprised $44 \%$ males $(11 / 25)$. The mean age (SD) of the patients was $54( \pm 17)$ years. Indications for scanning were vasculitis $(n=15)$, suspected infection $(n=8)$, and suspected malignancy $(n=2)$. Within the test set, OA grades 0 to 3 were found in all joints, except for the hip and ankle, where only grades 0 to 2 were found (Table 2). Most joints were graded as having no OA or only mild OA, which is to be expected in a random sample of hospital. One ankle could not be scored due to beam-hardening artifacts caused by screws.

Table 2. Frequency of grades per joint ( $n=25$ patients).

\begin{tabular}{|c|c|c|c|c|c|c|c|c|}
\hline \multirow{2}{*}{$\begin{array}{l}\text { Joint } \\
\text { Acromioclavicular, } \mathrm{N}(\%)\end{array}$} & \multicolumn{2}{|c|}{0 (No) } & \multicolumn{2}{|c|}{1 (Mild) } & \multicolumn{2}{|c|}{2 (Moderate) } & \multicolumn{2}{|c|}{3 (Severe) } \\
\hline & 24 & $(48)$ & 10 & (20) & 5 & $(10)$ & 11 & $(22)$ \\
\hline Glenohumeral, N(\%) & 37 & (74) & 7 & (14) & 3 & (6) & 3 & (6) \\
\hline Intervertebral Disc, $\mathrm{N}(\%)$ & 48 & $(32)$ & 47 & (31) & 33 & (22) & 22 & (15) \\
\hline Facet, $\mathrm{N}(\%)$ & 91 & (61) & 37 & (25) & 7 & (5) & 15 & (10) \\
\hline Hip, N(\%) & 33 & (66) & 13 & (26) & 4 & (8) & 0 & (0) \\
\hline Knee, N(\%) & 25 & $(50)$ & 13 & (26) & 8 & (16) & 4 & (8) \\
\hline Patellofemoral, N(\%) & 25 & (50) & 15 & (30) & 5 & (10) & 5 & (10) \\
\hline Ankle $^{1}, \mathrm{~N}(\%)$ & 26 & (54) & 19 & (38) & 4 & (8) & 0 & $(0)$ \\
\hline
\end{tabular}

${ }^{1}$ One ankle was not scored due to artefacts caused by screws; Scores presented are produced in the first scoring round by WPG.

\subsection{Intra- and Interobserver Reliability for Total OA Grade}

Intra-observer reliability for total OA grade was excellent, with an ICC of 0.97 (95\% CI, 0.93 to 0.99 ). The Bland-Altman plot showed an even spread of errors between the first and second observation, with a mean error of -3.5 (SD, 3.4). Inter-observer reliability for total OA grade was also excellent, with an ICC of 0.94 (95\% CI, 0.86 to 0.98$)$. ICCs for inter-observer reliability were comparable between observer pairs of different proficiency levels, 0.95 between WPG and WF, 0.93 between WPG and FJN, and 0.97 between WF and FJN. The Jones plot showed an even spread of errors between all observers, with WF giving grades around the mean, FJN giving lower grades on average, and WPG giving higher grades on average (Figure 3). 


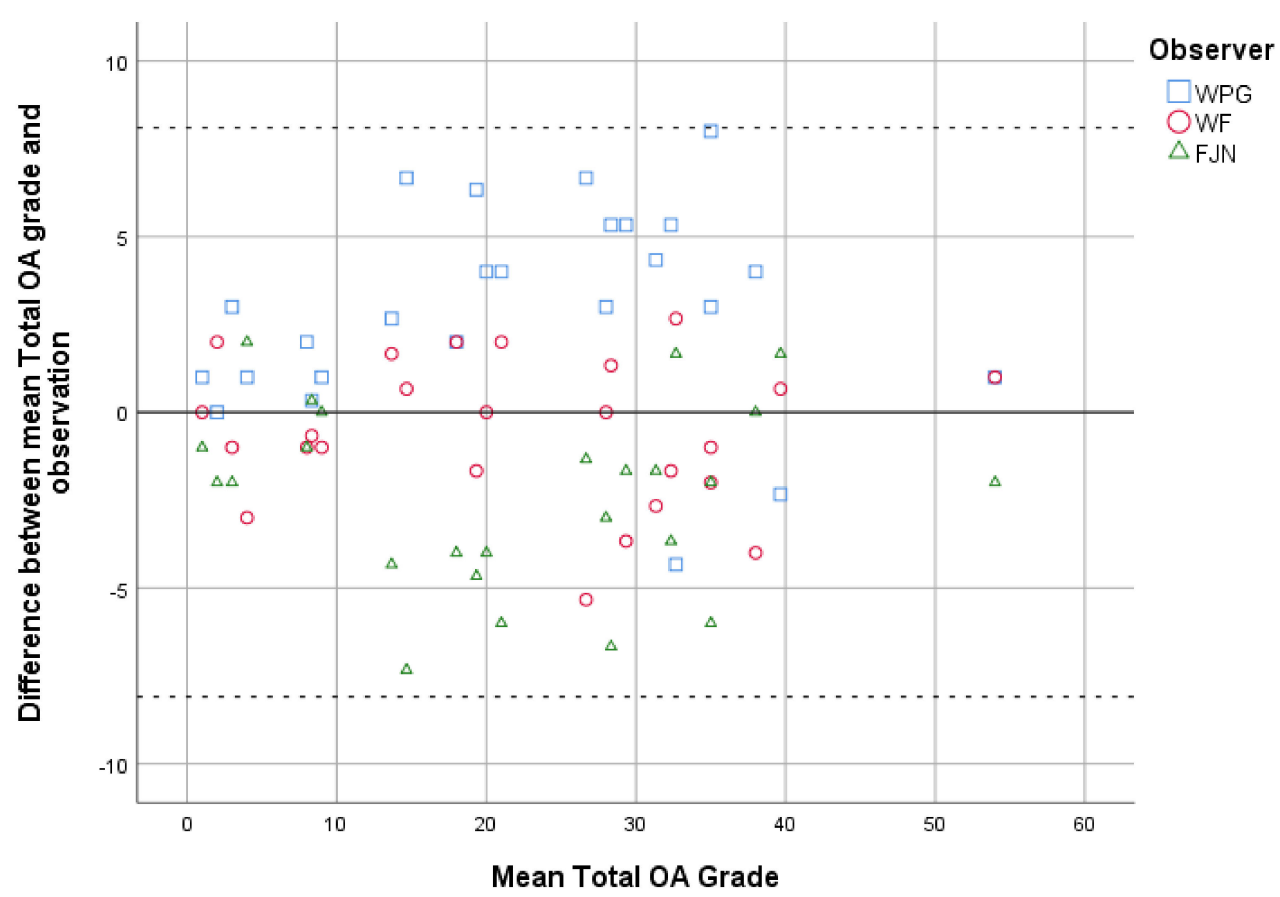

Figure 3. Jones plot depicting the difference between each observation of the different readers and the mean observed score for the total OA grade. The interrupted lines show the $95 \%$ limits of agreement.

\subsection{Intra- and Interobserver Reliability for OACT Scores for Individual Joints}

Intra-observer reliability of the OA grades for individual joints was substantial to almost perfect, with the kappa values ranging from 0.79 to 0.95 and absolute percentage agreement, ranging from $67 \%$ to $92 \%$ (Table 3). Inter-observer reliability of the OA grades for individual joints was moderate to almost perfect, with the kappa values ranging from 0.48 to 0.95 and absolute percentage agreement ranging from $36 \%$ to $90 \%$ (Table 3 ). Table A1 shows the intra- and inter-observer reliability for grading of individual OA characteristics (joint space narrowing, osteophytosis, and so on).

Table 3. Intra- and interobserver reliability as weighted kappa (percentage of absolute agreement) for OACT scores for individual joints.

\begin{tabular}{llllllll}
\hline Joints & $\begin{array}{l}\text { Reader 1 } \\
\text { (intra) }\end{array}$ & \multicolumn{2}{l}{$\begin{array}{l}\text { Reader 1 vs. } \\
\text { Reader 2 }\end{array}$} & \multicolumn{2}{l}{$\begin{array}{l}\text { Reader 1 vs. } \\
\text { Reader 3 }\end{array}$} & \multicolumn{2}{l}{$\begin{array}{l}\text { Reader 2 vs. } \\
\text { Reader 3 }\end{array}$} \\
\hline Acromioclavicular & $0.84(80)$ & 0.87 & $(74)$ & 0.75 & $(62)$ & 0.82 & $(68)$ \\
Glenohumeral & $0.95(92)$ & 0.69 & $(72)$ & 0.58 & $(38)$ & 0.50 & $(48)$ \\
Intervertebral Disc & $0.85(67)$ & 0.80 & $(61)$ & 0.80 & $(68)$ & 0.77 & $(53)$ \\
Facet & $0.9 C(85)$ & 0.68 & $(64)$ & 0.66 & $(57)$ & 0.66 & $(57)$ \\
Hip & $0.85(88)$ & 0.53 & $(68)$ & 0.65 & $(64)$ & 0.48 & $(64)$ \\
Knee & $0.84(72)$ & 0.85 & $(68)$ & 0.73 & $(50)$ & 0.64 & $(36)$ \\
Patellofemoral & $0.94(88)$ & 0.95 & $(90)$ & 0.79 & $(60)$ & 0.78 & $(64)$ \\
Ankle & $0.79(84)$ & 0.74 & $(80)$ & 0.56 & $(65)$ & 0.49 & $(63)$ \\
\hline
\end{tabular}

Reader 1: Medical doctor and researcher; Reader 2: Radiologist in training with a subspecialization in musculoskeletal radiology; Reader 3: Fellowship-trained musculoskeletal radiologist with five years of experience.

\section{Discussion}

The OACT score described here-a new reproducible WBLDCT-based grading system for $\mathrm{OA}$ in large joints and the spine-was developed for research purposes. In this first step, we introduce the scoring methods and present a reference atlas with multiple example images. The atlas can be used as a reference for training new readers, educational purposes and systemic grading of OA on CT-scans. We demonstrated a satisfactory intra-observer reliability and decent inter-observer reliability. The use of WBLDCT for this goal is associ- 
ated with short scanning time with comparatively low-level exposure to ionizing radiation (effective radiation dose $<3 \mathrm{mSv}$ for a 70-kg adult male). Furthermore, with this newly developed grading system, it is possible to reliably assess overall structural burden of OA in a patient within $15 \mathrm{~min}$.

There is still no disease modifying drug for OA, mainly because drug development focused on finding a one-size-fits-all drug. Drug development and evaluation will have a higher chance of success if it is focused on specific structural phenotypes of OA. The selection criteria for these OA phenotypes has to be determined. The APPROACH study uses a combination of established and novel biomarkers to develop stratification models that can help select the appropriate therapy for each knee OA patient [3]. Many parameters, such as quality of life, physical performance and biochemical markers levels in serum or urine are affected by the disease burden of other joints [4,28-31]. These parameters potentially impact the efficacy of drug development and evaluation in OA. In the APPROACH study, the OACT score helps to phenotype OA patients and correct for confounding at the patient level when assessing the relation between systemic biomarkers, and e.g., knee OA. Besides structural progression, disease burden is an important marker for treatment success. Eventually the OACT-score will help improve patient selection for OA observational studies and clinical trials that include clinical outcome parameters. The clinical relevance needs to be established before clinical application may be considered. This has been the case for many other scoring-based assessment instrument in the field of $\mathrm{OA}$ that were primarily developed in the context of MRI evaluation [32,33]. Future studies should test the validity of the OACT-score against clinical outcome parameters and other biomarkers.

In our sample the total OACT score showed excellent intra- and inter-observer reliability (ICC, 0.97 , and 0.94 , respectively). To our knowledge, this is the first study test to reliability for an OA grade at patient level. However, we would like to stress that summing separate ordinal grades has limitations; for example, this would result in multiple lowgrade joints being equivalent to a single high-grade joint. For future studies, the weighting factors for composing a total score, reflecting OA throughout the body, should be altered to the goal of the specific study. Systemic cartilage degradation markers or global quality of life measurements could be used to assess the influences of the different joints on the total OA burden in future studies. Adding the OA scores of the joints of the hands and feet would undoubtedly improve the value of the scoring system; however, we did not do so because of the variable positioning of the hands and feet in the CT images in our study. Validated radiographic scores for OA of the hands and feet could be used in combination with the OACT score for a more complete assessment of total OA burden in the body [34].

The reliability results are in the expected range for a semi-quantitative radiological score for OA. For the acromioclavicular joint, we found substantial to almost perfect reliability. No other CT-based study is available for comparison. For the glenohumeral joint, inter-observer reliability was moderate to substantial, while the intra-observer reliability was almost perfect. We expect the moderate intra-observer reliability to be caused by the high prevalence of no and mild glenohumeral OA, as this emphasizes the decision between the presence of no, or a small $(<3 \mathrm{~mm})$ osteophyte. Again, no CT-based studies are available for comparison. We found almost perfect intra-observer reliability and substantial to almost perfect inter-observer reliability for DDD. No CT-based studies are available for comparison. While, OA and DDD are different entities, the response to mechanical loading, symptoms and matrix degradation pattern are highly correlated [35]. Therefore, we chose to include DDD in our score. Based on the aim of their study, researcher may decide to inor exclude DDD.

Pathria et al. tested the inter-observer reliability of their CT-based scoring system for facet joint OA and reported a kappa value of 0.46 , while Weishaupt et al. reported a weighted kappa of 0.60 [16,17]; the overall percentage agreement was $63 \%$, and $51 \%$, respectively. These results were comparable to our results, where the weighted kappa values ranged from 0.66 to 0.68 and absolute percentage agreement ranged from $57 \%$ to $64 \%$. 
Turmezei et al. tested the reliability of their CT grading system for hip OA and reported a weighted kappa of 0.74 and 0.75 for intra- and inter-observer reliability, respectively. We simplified their scoring system to enhance grading speed and reliability for new readers and found a weighted kappa of 0.85 for intra-observer reliability and between 0.48 and 0.65 for inter-observer reliability. The lower inter-observer reliability in our study may be due to the very low prevalence of hip OA in our study population $(8 \%$ with moderate OA or higher) compared to the study population of Turmezei et al., which was selected to include the full spectrum of hip OA.

For both patella and knee OA, we found almost perfect intra-observer reliability and substantial to almost perfect inter-observer reliability. For the ankle joint, we found moderate to substantial inter-observer agreement. Cohen et al. introduced an atlas for grading ankle osteoarthritis on CT and reported an ICC of 0.851 and unweighted kappa of 0.582 in a population of specifically selected scans. As such, a valid comparison with our results is not possible.

Our scoring system has several limitations. First, it does not consider OA in the elbows, hands, and feet. The elbow was not included in our score as it was positioned outside the field of view in a large number of scans. However, it should be noted that elbow OA is rare, with a prevalence of only $~ 2 \%$ [36]. Second, we used semi-quantitative grades. However, it must be noted that semi-quantitative grading enabled scoring a full WBLDCT in $15 \mathrm{~min}$. Third, WBLDCT is obtained with the patient lying supine; assessment of joint space is influenced by the lack of weight bearing. The development of weight-bearing CTscan will hopefully counter this problem in the near future. Fourth, WBLDCT can clearly visualize bony changes, but soft tissue degeneration (e.g., meniscal and capsule tears) will be missed. Fifth, concurrent pathology such as diffuse idiopathic skeletal hyperostosis may aggravate OA scores. Grading systems for such concurrent diseases could be used along with the OA scores to further characterize individuals [37-39]. Sixth, CT involves exposure to possibly harmful ionizing radiation. Due to technical advances, including iterative reconstruction, the effective radiation dose of the WBLDCT was around $\leq 3 \mathrm{mSv}$, which approximates one year of background radiation [40]. The exact risk for excess death by cancer to a given effective radiation dose is difficult to determine. Using the rule of $5 \%$ excess mortality per $1 \mathrm{~Sv}$, each WBLDCT may be accompanied by a $0.00015 \%$ excess risk for cancer mortality [41]. Determining the sample size for a reproducibility study using weighted kappa statistics is not straightforward [24]. We deemed a sample of 25 as appropriate since this results in a minimum of 50 joints per analysis and a total time invested for training and scoring of $\sim 10 \mathrm{~h}$ per reader. For the analysis of the total OA grade, only 25 cases were available, which partly explains the high standard deviations in the Bland-Altman and Jones plots.

\section{Conclusions}

To summarize, we introduce the OACT score, a WBLDCT-based reproducible grading system for large-joint OA burden in the body. The OACT score can be used as an outcome measure in OA research or to correct for the influence of total OA burden on patient reported outcomes and biochemical marker levels.

Supplementary Materials: The following are available online at https:/ /www.mdpi.com/2075-442 6/11/1/5/s1, The reference atlas is found in Appendix A.

Author Contributions: All authors contributed to the study design, interpretation of the data, and approved of the final version submitted for publication. W.P.G. and W.F. contributed to the first draft of the manuscript and formal analysis. F.J.N., H.W. and F.J.N. substantively reviewed and revised the manuscript. W.P.G., F.J.N., F.W.R. and W.F. developed the scoring system and contributed data acquisition for reproducibility testing. H.W. was responsible for resources and funding acquisition. All authors have read and agreed to the published version of the manuscript.

Funding: This work was supported by Reuma Nederland (LLP-22) and the APPROACH project. APPROACH has received support from the Innovative Medicines Initiative Joint Undertaking under 
Grant Agreement $\mathrm{n}^{\circ} 115770$, resources of which are composed of financial contribution from the European Union's Seventh Framework Programme (FP7/2007-2013) and EFPIA companies' in kind contribution. See www.imi.europa.eu.

Data Availability Statement: The data presented in this study are available on request from the corresponding author. The data are not publicly available due to ongoing unpublished research.

Acknowledgments: We would like to thank Chris van Kesteren for his work on the graphical abstract.

Conflicts of Interest: FWR is shareholder of Boston Imaging Core Lab (BICL), LLC., a company providing image assessment services to academia and the pharmaceutical industry. This did not impact any of the current findings.

\section{Appendix A}

Table A1. Intra- and interobserver reliability for grading of individual characteristics.

\begin{tabular}{|c|c|c|c|c|c|c|c|}
\hline \multirow{2}{*}{$\begin{array}{l}\text { Intervertebral Disc } \\
\text { Weighted Kappa (\% } \\
\text { agreement) } \\
\text { Disc space narrowing (0-3) }\end{array}$} & \multirow{2}{*}{$\begin{array}{l}\begin{array}{l}\text { Reader } 1 \\
\text { (intra) }\end{array} \\
0.83(65)\end{array}$} & \multicolumn{2}{|c|}{$\begin{array}{l}\text { Reader } 1 \text { vs. } \\
\text { Reader } 2\end{array}$} & \multicolumn{2}{|c|}{$\begin{array}{l}\text { Reader } 1 \text { vs. } \\
\text { Reader } 3\end{array}$} & \multicolumn{2}{|c|}{$\begin{array}{l}\text { Reader } 2 \text { vs. } \\
\text { Reader } 3\end{array}$} \\
\hline & & 0.76 & $(57)$ & 0.80 & (63) & 0.72 & $(50)$ \\
\hline Osteophytes (0-3) & $0.85(73)$ & 0.76 & (65) & 0.76 & (51) & 0.81 & $(65)$ \\
\hline $\begin{array}{l}\text { Sclerosis and/or end plate } \\
\text { irregularity (0-1) } \\
\text { Hip } \\
\text { Weighted kappa (\% } \\
\text { agreement) }\end{array}$ & $0.68(84)$ & 0.56 & $(79)$ & 0.58 & (79) & 0.45 & $(72)$ \\
\hline Joint space narrowing $(0-3)$ & $0.86(82)$ & 0.65 & $(64)$ & 0.37 & $(64)$ & 0.51 & $(54)$ \\
\hline Osteophytes (0-3) & $0.75(80)$ & 0.57 & $(72)$ & 0.69 & (74) & 0.59 & $(70)$ \\
\hline Cyst (0-1) & $1.00(100)$ & 1.00 & $(100)$ & 0.49 & $(96)$ & 0.49 & $(96)$ \\
\hline \multicolumn{8}{|l|}{$\begin{array}{l}\text { Tibiofemoral joint } \\
\text { Weighted kappa (\% } \\
\text { agreement) }\end{array}$} \\
\hline Joint space narrowing $(0-3)$ & $0.77(64)$ & 0.63 & $(52)$ & 0.74 & $(58)$ & 0.45 & $(38)$ \\
\hline Osteophytes (0-3) & $0.90(78)$ & 0.90 & (78) & 0.85 & $(60)$ & 0.86 & (68) \\
\hline Cyst (0-1) & $0.81(94)$ & 0.38 & $(80)$ & 0.31 & (72) & 0.44 & (76) \\
\hline
\end{tabular}

Reader 1: Medical doctor and researcher; Reader 2: Radiologist in training with a subspecialization in musculoskeletal radiology; Reader 3: Fellowship-trained musculoskeletal radiologist with five years of experience.

\section{References}

1. Hunter, D.J.; Schofield, D.; Callander, E. The individual and socioeconomic impact of osteoarthritis. Nat. Rev. Rheumatol. 2014, 10, 437-441. [CrossRef]

2. Van Spil, W.E.; Kubassova, O.; Boesen, M.; Bay-Jensen, A.C.; Mobasheri, A. Osteoarthritis phenotypes and novel therapeutic targets. Biochem. Pharmacol. 2019, 165, 41-48. [CrossRef]

3. APPROACH Project. Available online: https://www.approachproject.eu (accessed on 8 March 2019).

4. Kraus, V.B.; Kepler, T.B.; Stabler, T.; Renner, J.; Jordan, J. First qualification study of serum biomarkers as indicators of total body burden of osteoarthritis. PLOS ONE 2010, 5, e9739. [CrossRef]

5. Meulenbelt, I.; Kloppenburg, M.; Kroon, H.M.; Houwing-Duistermaat, J.J.; Garnero, P.; Hellio-Le Graverand, M.-P.; DeGroot, J.; Slagboom, P.E. Clusters of biochemical markers are associated with radiographic subtypes of osteoarthritis (OA) in subject with familial OA at multiple sites. The GARP study. Osteoarthr. Cartil. 2007, 15, 379-385. [CrossRef]

6. $\quad$ Kinds, M.B.; Vincken, K.L.; Hoppinga, T.N.; Bleys, R.L.A.W.; Viergever, M.A.; Marijnissen, A.C.A.; Welsing, P.M.J.; Lafeber, F.P.J.G. Influence of variation in semiflexed knee positioning during image acquisition on separate quantitative radiographic parameters of osteoarthritis, measured by Knee Images Digital Analysis. Osteoarthr. Cartil. 2012. [CrossRef]

7. Willemink, M.J.; Leiner, T.; de Jong, P.A.; de Heer, L.M.; Nievelstein, R.A.J.; Schilham, A.M.R.; Budde, R.P.J. Iterative reconstruction techniques for computed tomography part 2: Initial results in dose reduction and image quality. Eur. Radiol. 2013, 23, 1632-1642. [CrossRef] [PubMed] 
8. Willemink, M.J.; de Jong, P.A.; Leiner, T.; de Heer, L.M.; Nievelstein, R.A.J.; Budde, R.P.J.; Schilham, A.M.R. Iterative reconstruction techniques for computed tomography Part 1: Technical principles. Eur. Radiol. 2013, 23, 1623-1631. [CrossRef] [PubMed]

9. Weiler, C.; Schietzsch, M.; Kirchner, T.; Nerlich, A.G.; Boos, N.; Wuertz, K. Age-related changes in human cervical, thoracal and lumbar intervertebral disc exhibit a strong intra-individual correlation. Eur. Spine J. 2012, 21 (Suppl. 6), S810-S818. [CrossRef]

10. O'Neill, T.W.; McCloskey, E.V.; Kanis, J.a.; Bhalla, A.K.; Reeve, J.; Reid, D.M.; Todd, C.; Woolf, A.D.; Silman, A.J. The distribution, determinants, and clinical correlates of vertebral osteophytosis: A population based survey. J. Rheumatol. 1999, 26, 842-848. [PubMed]

11. Stenlund, B.; Marions, O.; Engström, K.F.; Goldie, I. Correlation of macroscopic osteoarthrotic changes and radiographic findings in the acromioclavicular joint. Acta Radiol. 1988, 29, 571-576. [CrossRef] [PubMed]

12. Elsharkawi, M.; Cakir, B.; Reichel, H.; Kappe, T. Reliability of radiologic glenohumeral osteoarthritis classifications. J. Shoulder Elbow Surg. 2013, 22, 1063-1067. [CrossRef] [PubMed]

13. Samilson, R.L.; Prieto, V. Dislocation arthropathy of the shoulder. J. Bone Joint Surg. Am. 1983, 65, 456-460. [CrossRef] [PubMed]

14. Lane, N.E.; Nevitt, M.C.; Genant, H.K.; Hochberg, M.C. Reliability of new indices of radiographic osteoarthritis of the hand and hip and lumbar disc degeneration. J. Rheumatol. 1993, 20, 1911-1918. [PubMed]

15. Kettler, A.; Wilke, H.-J. Review of existing grading systems for cervical or lumbar disc and facet joint degeneration. Eur. Spine J. 2006, 15, 705-718. [CrossRef] [PubMed]

16. Weishaupt, D.; Zanetti, M.; Boos, N.; Hodler, J. MR imaging and CT in osteoarthritis of the lumbar facet joints. Skelet. Radiol. 1999, 28, 215-219. [CrossRef]

17. Pathria, M.; Sartoris, D.J.; Resnick, D. Osteoarthritis of the facet joints: Accuracy of oblique radiographic assessment. Radiology 1987, 164, 227-230. [CrossRef]

18. Turmezei, T.D.; Fotiadou, A.; Lomas, D.J.; Hopper, M.a.; Poole, K.E.S. A new CT grading system for hip osteoarthritis. Osteoarthr. Cartil. 2014, 22, 1360-1366. [CrossRef]

19. Altman, R.D.; Gold, G.E. Atlas of individual radiographic features in osteoarthritis, revised. Osteoarthr. Cartil. 2007, 15 (Suppl. A), A1-A56. [CrossRef]

20. Kellgren, J.H.; Lawrence, J.S. Radiological assessment of osteo-arthrosis. Ann. Rheum. Dis. 1957, 16, 494-502. [CrossRef]

21. Jones, A.C.; Ledingham, J.; Mcalindon, T.; Regan, M.; Hart, D.; Macmillan, P.J.; Doherty, M. Radiographic assessment of patellofemoral osteoarthritis. Ann. Rheum. Dis. 1993, 52, 655-658. [CrossRef]

22. Cohen, M.M.; Vela, N.D.; Levine, J.E.; Barnoy, E.A. Validating a New Computed Tomography Atlas for Grading Ankle Osteoarthritis. J. Foot Ankle Surg. 2014, 54, 207-213. [CrossRef] [PubMed]

23. Fleiss, J.L.; Cohen, J. The equivalence of weighted kappa and the intraclass correlation coefficient as measures of reliability. Educ. Psychol. Meas. 1973, 33, 613-619. [CrossRef]

24. Kottner, J.; Audigé, L.; Brorson, S.; Donner, A.; Gajewski, B.J.; Hróbjartsson, A.; Roberts, C.; Shoukri, M.; Streiner, D.L. Guidelines for Reporting Reliability and Agreement Studies (GRRAS) were proposed. J. Clin. Epidemiol. 2011, 64, 96-106. [CrossRef] [PubMed]

25. Landis, J.R.; Koch, G.G. The Measurement of Observer Agreement for Categorical Data. Biometrics 1977, 33, 159. [CrossRef]

26. Martin Bland, J.; Altman, D. Statistical methods for assessing agreement between two methods of clinical measurement. Lancet 1986, 327, 307-310. [CrossRef]

27. Jones, M.; Dobson, A.; O'Brian, S. A graphical method for assessing agreement with the mean between multiple observers using continuous measures. Int. J. Epidemiol. 2011, 40, 1308-1313. [CrossRef]

28. Mahir, L.; Belhaj, K.; Zahi, S.; Azanmasso, H.; Lmidmani, F.; El Fatimi, A. Impact of knee osteoarthritis on the quality of life. Ann. Phys. Rehabil. Med. 2016, 59, e159. [CrossRef]

29. Glazebrook, M.; Daniels, T.; Younger, A.; Foote, C.J.; Penner, M.; Wing, K.; Lau, J.; Leighton, R.; Dunbar, M. Comparison of Health-Related Quality of Life Between Patients with End-Stage Ankle and Hip Arthrosis. J. Bone Jt. Surg.-Am. Vol. 2008, 90, 499-505. [CrossRef]

30. Gautschi, O.P.; Smoll, N.R.; Corniola, M.V.; Joswig, H.; Chau, I.; Hildebrandt, G.; Schaller, K.; Stienen, M.N. Validity and reliability of a measurement of objective functional impairment in lumbar degenerative disc disease: The Timed Up and Go (TUG) test. Neurosurgery 2016, 79, 270-278. [CrossRef]

31. Dobson, F.; Hinman, R.S.; Hall, M.; Terwee, C.B.; Roos, E.M.; Bennell, K.L. Measurement properties of performance-based measures to assess physical function in hip and knee osteoarthritis: A systematic review. Osteoarthr. Cartil. 2012, 20, 1548-1562. [CrossRef]

32. Peterfy, C.G.; Guermazi, A.; Zaim, S.; Tirman, P.F.J;; Miaux, Y.; White, D.; Kothari, M.; Lu, Y.; Fye, K.; Zhao, S.; et al. Whole-organ magnetic resonance imaging score (WORMS) of the knee in osteoarthritis. Osteoarthr. Cartil. 2004, 12, 177-190. [CrossRef] [PubMed]

33. Hunter, D.J.; Guermazi, A.; Lo, G.H.; Grainger, A.J.; Conaghan, P.G.; Boudreau, R.M.; Roemer, F.W. Evolution of semi-quantitative whole joint assessment of knee OA: MOAKS (MRI Osteoarthritis Knee Score). Osteoarthr. Cartil. 2011, 19, 990-1002. [CrossRef] [PubMed]

34. Visser, A.W.; Bøyesen, P.; Haugen, I.K.; Schoones, J.W.; van der Heijde, D.M.; Rosendaal, F.R.; Kloppenburg, M. Radiographic scoring methods in hand osteoarthritis-A systematic literature search and descriptive review. Osteoarthr. Cartil. 2014, 22, 1710-1723. [CrossRef] [PubMed] 
35. Rustenburg, C.M.E.; Emanuel, K.S.; Peeters, M.; Lems, W.F.; Vergroesen, P.-P.A.; Smit, T.H. Osteoarthritis and intervertebral disc degeneration: Quite different, quite similar. JOR Spine 2018, 1, e1033. [CrossRef] [PubMed]

36. Gramstad, G.D.; Galatz, L.M. Management of Elbow Osteoarthritis. J. Bone Jt. Surg. 2006, 88, 421-430. [CrossRef]

37. Kuperus, J.S.; Oudkerk, S.F.; Foppen, W.; Mohamed Hoesein, F.A.; Gielis, W.P.; Waalwijk, J.; Regan, E.A.; Lynch, D.A.; Oner, F.C.; de Jong, P.A.; et al. Criteria for Early-Phase Diffuse Idiopathic Skeletal Hyperostosis: Development and Validation. Radiology 2019, 291, 420-426. [CrossRef]

38. Meinberg, E.; Agel, J.; Roberts, C.; Karam, M.; Kellam, J. Fracture and Dislocation Classification Compendium-2018. J. Orthop. Trauma 2018, 32, S1-S10. [CrossRef]

39. Chanchairujira, K.; Chung, C.B.; Kim, J.Y.; Papakonstantinou, O.; Lee, M.H.; Clopton, P.; Resnick, D. Intervertebral Disk Calcification of the Spine in an Elderly Population: Radiographic Prevalence, Location, and Distribution and Correlation with Spinal Degeneration. Radiology 2004, 230, 499-503. [CrossRef]

40. Mettler, F.A.; Huda, W.; Yoshizumi, T.T.; Mahesh, M. Effective doses in radiology and diagnostic nuclear medicine: A catalog. Radiology 2008, 248, 254-263. [CrossRef]

41. Lin, E.C. Radiation risk from medical imaging. Mayo Clin. Proc. 2010, 85, 1142-1146. [CrossRef] 